\title{
X-RAY STRUCTURE OF AN AMIDE-APPENDED CHLOROMERCURATED DERIVATIVE OF 2-PHENYLQUINOLINE
}

\author{
C.-Y. Lin, W. Henderson, B.K. Nicholson \\ Department of Chemistry, School of Science, University of Waikato, Hamilton, New Zealand \\ E-mail: w.henderson@waikato.ac.nz \\ Received February, 03, 2014
}

\begin{abstract}
Reaction of the morpholine amide derivative of 2-phenyl-4-quinolinecarboxylic acid with mercury(II) acetate and lithium chloride results in chloromercuration at the ortho position on the phenyl ring; the complex was characterised by ESI mass spectrometry and an X-ray structure determination.
\end{abstract}

DOI: $10.15372 / J S C 20150518$

K e y w o r d s: synthesis, mercury complexes, orthometallation reactions, crystal structure.

\section{INTRODUCTION}

Organomercury compounds have found to be versatile reagents for the synthesis of a wide range of cycloaurated gold(III) complexes through transmetallation reactions [1]. The transmetallation synthesis of cycloaurated gold complexes has been applied to a wide range of systems, including substituted pyridines, azobenzenes, oxazolines, and $N, N$-dimethylbenzylamines among others $[1,2]$. One of the precursors that has been orthomercurated and converted to a cycloaurated gold complex is the methyl ester of 2-phenyl-4-quinolinecarboxylic acid 1 [3]. We are interested in the chemistry of this precursor because it offers an opportunity to easily modify the solubility characteristics via the carboxylic acid functionality. This is significant because some cycloaurated gold(III) complexes can have relatively poor solubilities in common solvents. To date, only the methyl ester of 2-phenyl-4-quinolinecarboxylic acid has been converted (via orthomercurated precursor 2) into cycloaurated gold(III) complex 3. In this paper, the feasibility of orthomercurating amide derivatives is exemplified by the synthesis and structural characterization of a mercurated morpholine derivative of 2-phenyl-4-quinolinecarboxylic acid $\mathbf{1}$.

\section{EXPERIMENTAL}

Electrospray mass spectra were recorded in a dichloromethane-methanol solution using a Bruker MicrOTOF instrument, calibrated with $\mathrm{NaHCO}_{2}$, and employing a capillary exit voltage of $150 \mathrm{~V}$. NMR spectra were recorded in a $\mathrm{CDCl}_{3}$ solution on Bruker AVIII400 using the Topspin 3.0 software. Elemental microanalyses were from the Campbell Microanalytical Laboratory, University of Otago. 2-Phenyl-4-quinolinecarboxylic acid (Aldrich), mercury(II) acetate (BDH), lithium chloride (BDH), morpholine (Aldrich), and thionyl chloride (Riedel de Häen) were used as supplied.

Synthesis of 4. The following reaction was carried out using a Schlenk line with a supply of dry nitrogen gas. 2-Phenyl-4-quinolinecarboxylic acid 1a $(3.28 \mathrm{~g}, 13.2 \mathrm{mmol})$ was refluxed in thionyl chloride (5 ml, excess) for $1 \mathrm{~h}$. The resulting bright yellow solution was evaporated to dryness under reduced pressure to give carboxylic acid chloride as a bright yellow solid which was used without fur-

(C) Lin C.-Y., Henderson W., Nicholson B.K., 2015 
ther purification. The acid chloride was cooled in an ice bath and morpholine $(5 \mathrm{ml})$ was added dropwise with stirring. After the addition, hexane $(5 \mathrm{ml})$ and dichloromethane $(5 \mathrm{ml})$ were added with stirring, followed by an additional portion of morpholine $(5 \mathrm{ml})$. The mixture was stirred for 5 days, giving a milky white solution, which was then evaporated to dryness in the air; subsequent operations were carried out in the air. The product was crystallized from a hot ethanol-water mixture (70:30), with excess sodium chloride added to aggregate the milky precipitate formed. A second recrystallization from the hot ethanol-water mixture (70:30) produced an off-white solid of $4(3.24 \mathrm{~g}, 77 \%)$. Found (\%): C 75.19, H 5.71, N 8.76. $\mathrm{C}_{20} \mathrm{H}_{18} \mathrm{~N}_{2} \mathrm{O}_{2}$ requires (\%) C 75.46, H 5.70, N 8.80. M.p. 128$130{ }^{\circ} \mathrm{C}$. Positive-ion ESI MS, $[\mathrm{MH}]^{+}\left(\mathrm{m} / \mathrm{z} 319.227\right.$, calculated 319.144), [MNa] ${ }^{+}$( $\mathrm{m} / \mathrm{z} 341.214$, calculated 341.126), $\left[\mathrm{M}_{2} \mathrm{Na}\right]^{+}\left(\mathrm{m} / z\right.$ 659.418, calculated 659.263). ${ }^{1} \mathrm{H}$ NMR $\left(\mathrm{CDCl}_{3}\right), \delta 3.22-3.26(\mathrm{~m}, 2 \mathrm{H}$, $\left.\mathrm{CH}_{2}\right), 3.53-3.58\left(\mathrm{~m}, 2 \mathrm{H}, \mathrm{CH}_{2}\right), 3.86-3.92\left(\mathrm{~m}, 2 \mathrm{H}, \mathrm{CH}_{2}\right), 4.03-4.06\left(\mathrm{~m}, 2 \mathrm{H}, \mathrm{CH}_{2}\right), 7.47-7.61(\mathrm{~m}$, $5 \mathrm{H}), 7.76-7.86(\mathrm{~m}, 5 \mathrm{H}), 8.15-8.18(\mathrm{~m}, 1 \mathrm{H}), 8.21-8.23(\mathrm{~m}, 1 \mathrm{H})$.

Synthesis of 5. To compound $4(2.00 \mathrm{~g}, 6.29 \mathrm{mmol})$ in ethanol $(40 \mathrm{ml})$ was added mercury(II) acetate $(2.00 \mathrm{~g}, 6.28 \mathrm{mmol})$, and the mixture was refluxed for $14 \mathrm{~h}$ to give a milky-white cloudy solution. The hot mixture was filtered into a solution of lithium chloride $(0.38 \mathrm{~g}, 8.90 \mathrm{mmol})$ in ethanol $(5 \mathrm{ml})$, immediately giving a white solid. The mixture was refluxed for $2 \mathrm{~h}$, cooled to room temperature and allowed to stand for $16 \mathrm{~h}$. Water $(200 \mathrm{ml})$ was added and the white solid filtered and washed with water. Recrystallization by vapour diffusion of pentane into a dichloromethane solution gave solid product 5 (1.93 g, 55 \%). M.p. 226-230 ${ }^{\circ} \mathrm{C}$. Positive-ion ESI MS, [MNa] ${ }^{+}(\mathrm{m} / z$ 577.064, calcu-

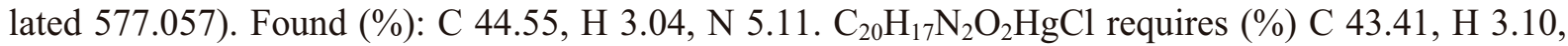
N 5.06. ${ }^{1} \mathrm{NMR}, \delta 3.23-3.27\left(\mathrm{~m}, 2 \mathrm{H}, \mathrm{CH}_{2}\right), 3.54-3.59\left(\mathrm{~m}, 2 \mathrm{H}, \mathrm{CH}_{2}\right), 3.87-3.92\left(\mathrm{~m}, 2 \mathrm{H}, \mathrm{CH}_{2}\right)$, 4.05-4.07 (m, 2H, $\left.\mathrm{CH}_{2}\right), 7.43-7.66(\mathrm{~m}, 4 \mathrm{H}), 7.77-7.86(\mathrm{~m}, 5 \mathrm{H}), 8.14-8.17(\mathrm{~m}, 1 \mathrm{H}), 8.24-8.25$ $(\mathrm{m}, 1 \mathrm{H})$.

X-ray crystal structure determination of 5 . The compound was recrystallized by vapour diffusion of diethyl ether into a chloroform solution at room temperature, giving colourless single crystals suitable for an X-ray diffraction study. Data (21919 reflections collected, 4825 independent reflections, $R_{\text {int }} 0.0391$ ) were collected on a crystal with dimensions of $0.60 \times 0.13 \times 0.06 \mathrm{~mm}$ at $89(2) \mathrm{K}$ on a Bruker SMART CCD diffractometer and processed using the standard software. An absorption correction was carried out using SADABS [4]. The structure was solved using SHELX-97 and refined on $F^{2}$ using SHELXL-97 [ 5 ] operated under WinGX [ 6], giving final $R$ indices $R_{1} 0.0360, \mathrm{w} R_{2} 0.0656$ for data with $[I>2 \sigma(I)]$ and $R_{1} 0.0335, \mathrm{w} R_{2} 0.0694$ (all data). All non-hydrogen atoms were treated anisotropically and hydrogen atoms were included with a riding model with $d(\mathrm{C}-\mathrm{H}) 0.95 \AA, U_{\text {iso }}=$ $=1.2 U_{\mathrm{eq}}(\mathrm{C})$ for aromatic hydrogen atoms. Residual electron density $\left(\mathrm{e} / \AA^{3}\right) \mathrm{max} / \mathrm{min}: 2.496 /-1.712$.

Crystal data: $\mathrm{C}_{20} \mathrm{H}_{17} \mathrm{ClHgN}_{2} \mathrm{O}_{2}, \quad M=553.40$, triclinic, space group $P-1, \quad a=9.5893(4) \AA$, $b=9.8519(4) \AA, c=10.1798(5) \AA, \alpha=107.494(2)^{\circ}, \beta=92.149(2)^{\circ}, \gamma=102.002(2)^{\circ}, V=892.01(7) \AA^{3}$, $Z=2, D_{\mathrm{c}}=2.060 \mathrm{~g} / \mathrm{cm}^{3}, \mu\left(\mathrm{Mo} K_{\alpha}\right)=8.794 \mathrm{~mm}^{-1}, F(000)=528$.

A CIF file containing complete information on the studied structure was deposited with CCDC, deposition number 976914, and is freely available from the web page http://www.ccdc.cam.ac.uk/data_request/cif.

\section{RESULTS AND DISCUSSION}

2-Phenyl-4-quinolinecarboxylic acid 1 was converted into its morpholine amide derivative $\mathbf{4}$ by a two-step procedure involving conversion to the acid chloride, followed by reaction with excess morpholine, as summarised in Scheme 1. The compound shows unexceptional spectroscopic features; the $\mathrm{CH}_{2}$ protons of the morpholine group appear as four distinct multiplets, due to the typical restricted rotation about the $\mathrm{C}(\mathrm{O})-\mathrm{N}$ moiety. Although compound $\mathbf{4}$ has been previously prepared [ 7 ] it has not been orthomercurated. Mercuration was achieved by the standard procedure, involving a reaction with mercury(II) acetate in refluxing ethanol, followed by conversion to the chloride complex with $\mathrm{LiCl}$ (Scheme 1), giving 5 as a white solid. The complex gave the expected NMR spectroscopic properties, and the positive ion ESI mass spectrum showed $[\mathrm{MNa}]^{+}$ions, with good agreement between the observed and calculated $\mathrm{m} / \mathrm{z}$ values, with the expected isotopic pattern due to the presence of polyisotopic mercury. 
<smiles>O=C(O)c1cc(-c2ccccc2)nc2ccccc12</smiles>

1<smiles></smiles>

6<smiles>O=C(O)c1cc(-c2ccccc2)nc2ccccc12</smiles>

1<smiles></smiles>

2<smiles></smiles>

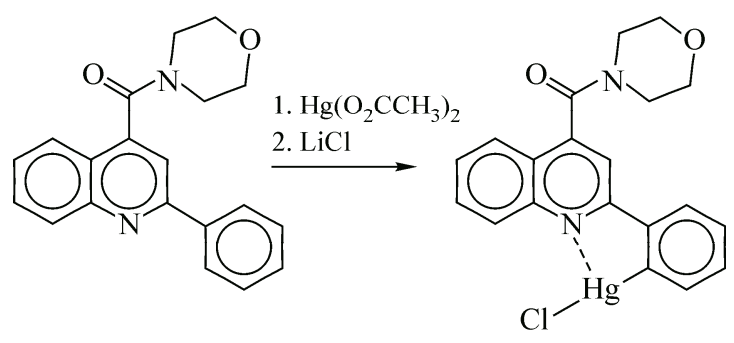

4

Scheme 1. Synthesis of organomercury derivative 5

To fully characterize mercury complex $\mathbf{5}$, an X-ray structure determination was carried out; there have been several structure determinations on ortho-mercurated 2-phenylpyridine $6[8,9]$ and derivatives thereof [ 10 ], and phenyl-substituted 1,10-phenanthroline [11], but there have been no prior determinations on orthomercurated 2-phenylquinolines. The structure is shown in Fig. 1, together with selected bond lengths and angles. The structure determination confirms chloromercuration at the ortho position of the phenyl ring, analogous to the previous reactivity in the ester analogue.

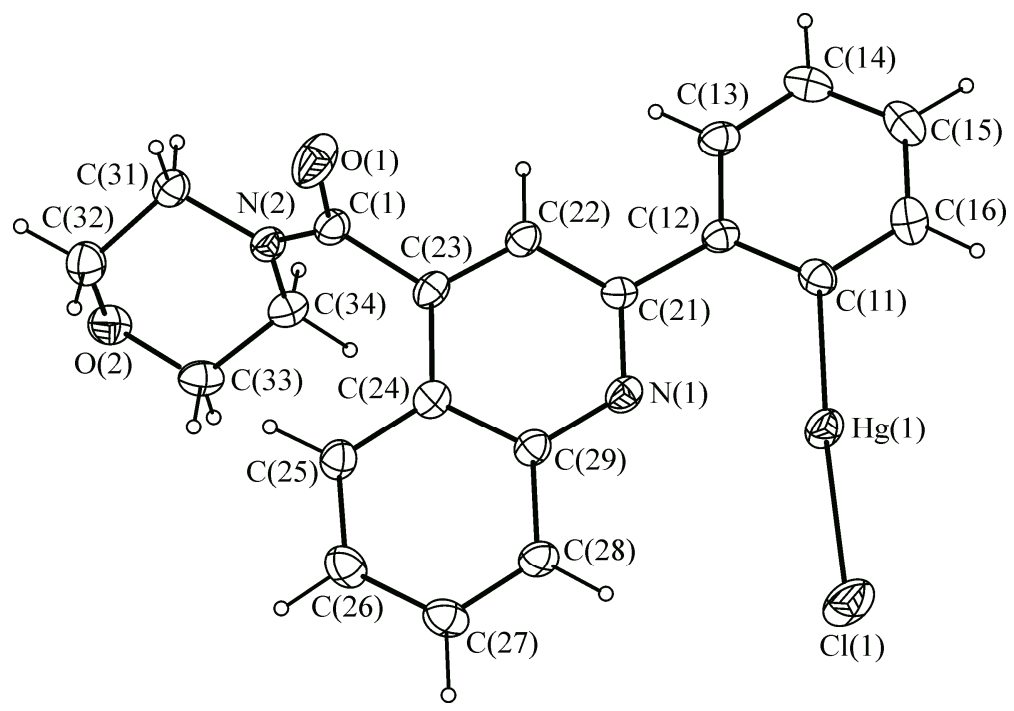

Fig. 1. Molecular structure of 5 showing the atom numbering scheme; thermal ellipsoids are shown at the $50 \%$ probability level, with the exception of hydrogen atoms shown as small open circles. Selected bond lengths $(\AA)$ and angles (deg.): $\mathrm{Hg}(1)-\mathrm{C}(11) 2.066(4), \mathrm{Hg}(1)-\mathrm{Cl}(1) 2.3166(10), \mathrm{Hg}(1) \cdots \mathrm{N}(1) 2.635(3), \mathrm{N}(1)-\mathrm{C}(21)$ 1.324(4), $\mathrm{N}(1)-\mathrm{C}(29) 1.365(5), \mathrm{N}(2)-\mathrm{C}(1) 1.348(5), \mathrm{N}(2)-\mathrm{C}(31) 1.456(5), \mathrm{N}(2)-\mathrm{C}(34) 1.465(5), \mathrm{O}(1)-$ $\mathrm{C}(1)$ 1.227(5), $\mathrm{C}(1)-\mathrm{C}(23)$ 1.509(5), $\mathrm{C}(11)-\mathrm{Hg}(1)-\mathrm{Cl}(1)$ 175.01(10), $\mathrm{C}(11)-\mathrm{Hg}(1)-\mathrm{N}(1) \quad 74.10(13)$, $\mathrm{O}(1)-\mathrm{C}(1)-\mathrm{N}(2) 123.9(3), \mathrm{O}(1)-\mathrm{C}(1)-\mathrm{C}(23) 117.7(3), \mathrm{N}(2)-\mathrm{C}(1)-\mathrm{C}(23) 118.4(3)$ 
The $\operatorname{Hg}(1)-\mathrm{C}(11)$ mercury-carbon bond distance is $2.066(4) \AA$, which is typical, compared to, e.g., chloromercurated 2-phenylpyridine $6(2.069(13) \AA$ and 2.070(13) $\AA$ ), in two independent $\mathrm{Hg}$ centres $[8,9]$. In 5 the $\operatorname{Hg}(1)-\mathrm{Cl}(1)$ bond is $2.3166(10) \AA$, compared to the distances of 2.314(4) $\AA$ and $2.335(4) \AA$ in 6 . There is the typical weak interaction between the quinoline nitrogen N(1) atom and the mercury atom, with $\operatorname{Hg}(1) \cdots \mathrm{N}(1)$ being $2.635(3) \AA$. The phenyl and quinoline ring systems are not coplanar, with an interplanar angle of $15.30^{\circ}$; by comparison, the two independent molecules in 6 have interplanar angles between the phenyl and pyridyl rings of $9.00^{\circ}$ and $23.68^{\circ}[8,9]$. As a consequence, the mercury atom in $\mathbf{5}$ is displaced only by $0.016 \AA$ from the phenyl ring plane, but by $0.799 \AA$ out of the least-squares plane of the quinoline ring system, though this does not appear to change the $\mathrm{Hg} \cdots \mathrm{N}$ distance compared to 6 (2.673(12) $\AA$ and 2.627(12) $\AA$ in the two independent molecules) [ 8, 9 ]. The $\mathrm{C}(11)-\mathrm{Hg}(1)-\mathrm{Cl}(1)$ bond angle is $175.01(10)^{\circ}$, with the chloride being displaced away from the quinoline ring as a result of the $\mathrm{Hg} \cdots \mathrm{N}$ interaction.

The amide substituent is approximately planar, with an angle of only $4.4^{\circ}$ between the $\mathrm{C}(31)$ $\mathrm{N}(2)-\mathrm{C}(34)$ and $\mathrm{O}(1)-\mathrm{C}(1)-\mathrm{C}(23)$ planes, however the amide is not coplanar with the quinoline ring, which can be demonstrated by the $\mathrm{O}(1)-\mathrm{C}(1)-\mathrm{C}(23)-\mathrm{C}(22)$ torsion angle of $123.1(5)^{\circ}$. This distortion presumably minimizes steric interactions between the $\mathrm{CH}_{2}$ group and the hydrogen atom on carbon $\mathrm{C}(25)$ on the quinoline ring. The morpholine ring system has the typical puckered chair conformation.

A previous structure determination of orthomercurated 2-phenylpyridine $6[8,9]$ showed dimeric units assembled through weak $\mathrm{Hg} \cdots \mathrm{Cl}$ interactions, these then further assembling to form a tetramer. However, the examination of the structure of $\mathbf{5}$ reveals that the molecules of $\mathbf{5}$ do not form the same aggregates, with the closest intermolecular $\mathrm{Hg} \cdots \mathrm{Cl}$ contact being very long, at 5.880(1) $\AA$. In $\mathbf{5}$ the molecules stack on top of each other in a head-to-tail fashion, with a distance of about $3.7 \AA$ between the adjacent stacked molecules. The difference is presumably due to the larger aromatic systems of $\mathbf{5}$, which promote $\pi \cdots \pi$ interactions at the expense of $\mathrm{Hg} \cdots \mathrm{Cl}$ interactions.

The University of Waikato is acknowledged for financial support of this work, Pat Gread for assistance with mass spectrometry studies, and Dr. Tania Groutso (University of Auckland) for the X-ray data collection. W. Henderson thanks Prof. Paul Low (University of Durham) for generously providing facilities for writing this manuscript.

\section{REFERENCES}

1. Henderson W. // Adv. Organomet. Chem. - 2006. - 54. - P. 207.

2. Vicente J., Chicote M.T. // Inorg. Chim. Acta. - 1981. - 54. - P. L259; Vicente J., Chicote M.T., Bermúdez M.D. // Inorg. Chim. Acta. - 1982. - 63. - P. 35; Hüttel R., Konietzny A. // Chem. Ber. - 1973. - 106. - P. 2098; Calderazzo F., Dell'Amico D.B. // J. Organomet. Chem. - 1974. - 76. - P. C59; Monaghan P.K., Puddephatt R.J., Buckley R.G., Elsome A.M., Fricker S.P., Henderson G.R., Theobald B.R.C., Parish R.V., Howe B.P., Kelland L.R. // J. Med. Chem. - 1996. - 39. - P. 5208; Mack J., Ortner K., Abram U., Parish R.V. // Z. Anorg. Allg. Chem. - 1997. - 623. - P. 873; Bonnardel P.A., Parish R.V. // J. Organomet. Chem. - 1996. - 515. - P. 221; Bonnardel P.A., Parish R.V., Pritchard R.G. // J. Chem. Soc. Dalton Trans. - 1996. - P. 3185.

3. Parish R.V., Wright J.P., Pritchard R.G. // J. Organomet. Chem. - 2000. - 596. - P. 165.

4. Blessing R.H. // Acta Crystallogr. - 1995. - A51. - P. 33.

5. Sheldrick G.M. SHELXS-97 and SHELXL-97. - Universität Göttingen, Germany, 1997.

6. Farrugia L.J. // J. Appl. Crystallogr. - 1999. - 32. - P. 837.

7. Shankerrao S., Bodke Y.D., Upadhyay A., Nagaraja K.L., Kiran J.R., Satyanarayan N.D. // Org. Chem.: An Indian J. - 2012. - 8. - P. 24; Dubroeucq M.C., Le Fur G., Renault C. // Eur. Pat. App. - 1984. - EP 112776 A2 19840704; Kar A. // J. Pharmaceut. Sci. - 1983. - 72. - P. 1082.

8. Constable E.C., Leese T.A., Tocher D.A. // Chem. Commun. - 1989. - 570.

9. Constable E.C., Thompson A.M.W.C., Leese T.A., Reese D.G.J., Tocher D.A. // Inorg. Chim. Acta. - 1991. - 182. - P. 93.

10. Soro B., Stoccoro S., Minghetti G., Zucca A., Cinellu M.A., Gladiali S., Manassero M., Sansoni M. // Organometallics. - 2005. - 24. - P. 53; Djukic J.-P., Berger A., Duquenne M., Pfeffer M., de Cian A., KyritsakasGruber N., Vachon J., Lacour J. // Organometallics. - 2004. - 23. - P. 5757; Berger A., de Cian A., Djukic J.-P., Fischer J., Pfeffer M. // Organometallics. - 2001. - 20. - P. 3230.

11. Chan C.-W., Peng S.M., Che C.-M. // Inorg. Chem. - 1994. - 33. - P. 3656. 